\title{
A case of veno-occlusive disease of the liver in Britain associated with herbal tea consumption
}

\author{
J. O'D. McGEE, ${ }^{1}$ R. S. PATRICK, C. B. WOOD, AND L. H. BLUMGART \\ From the University Departments of Pathology and Surgery, Royal Infirmary, Glasgow
}

SYNOPSIS Veno-occlusive disease of the liver with clinical and pathological features similar to those of the condition occurring in the Caribbean is described in a young woman resident in Britain. The diagnosis was made from liver biopsies and hepatic venography and was confirmed at necropsy. Small amounts of pyrroliziding alkaloids were recovered from a sample of maté (Paraguay) tea, owned by the patient, to which she was addicted. It seems probable that the consumption of large amounts of this tea over a period of years was the cause of the hepatic disease.

The term veno-occlusive disease was introduced by Bras et al in 1954 to designate the condition well known in Jamaica particularly among children who suffer from portal hypertension with severe ascites due to obliteration of centrilobular and sublobular hepatic veins by newly formed connective tissue. Such changes can occur naturally in animals which have ingested food containing toxic alkaloids, for example, ragwort poisoning in cattle (Betty and Markson, 1954), and this strengthened the suspicion that the human disease may have a similar aetiology. It is now accepted that the Jamaican disease results from the ingestion of pyrrolizidine alkaloids present in senecio and crotalaria plants from which bush teas and certain herbal remedies are derived. These alkaloids, for example, monocrotaline and fulvine, induce hepatic venous occlusion in monkeys (Allen et $a l, 1969)$ and in rats if the dose is carefully adjusted (McLean et al, 1964).

While the disease is most prevalent in the Caribbean area similar but not identical conditions have been noted in Egypt and South Africa (Stein and Isaacson, 1962). In other countries veno-occlusive disease is very uncommon, especially if care is taken to distinguish it from Budd-Chiari syndrome due to obstruction of hepatic veins at their ostia. These rare sporadic cases are not usually associated with pyrrolizidine poisoning but with other factors such as oral contraceptives (Ecker et al, 1966; Sterup and Mosbech, 1967; Hoyumpa et al, 1971), urethane in the treatment of myeloma (Brodsky et al, 1961), and

\footnotetext{
1Present address: Department of Pathology, Gibson Laboratories, Radcliffe Infirmary, Oxford
}

Received for publication 19 February 1976 irradiation (Reed and Cox, 1966). The present case of veno-occlusive disease, which terminated fatally, occurred in a young woman who had consumed large quantities of herbal tea from which pyrrolizidine alkaloids were recovered. We know of only two similar cases occurring in this country to which brie reference has been made by Sherlock (1961).

\section{Case report}

A 26-year-old woman had suffered from episodes of upper abdominal pain for many months before admission; a barium meal during this period showed no evidence of peptic ulcer. On admission to hospital four months before death she appeared unwell although neither anaemic nor jaundiced. Ascites was evident and the liver was palpable three fingerbreadths below the costal margin. There was no splenomegaly. She had been drinking large quantities of herbal tea obtained from local health stores but gave no history of any other circumstances to which a liver disorder could be attributed; the tea, known as maté or Paraguay tea, is derived from a mixture of the leaves of various species of Ilex plants which have been sucked through a sliver of bamboo (maté). There was evidence of liver dysfunction, the results of standard tests being as follows: serum albumin $30 \mathrm{~g} / 1$; serum globulins $23 \mathrm{~g} / 1$; total bilirubin $13 \mu$ moles/1; AST 34 IU/1 (normal value 11-55 IU/1); ALT 28 IU/1 (13-43 IU/1); alkaline phosphatase 303 IU/1 (80-280 IU/1). A mild extrinsic and intrinsic coagulation defect was noted after one week in hospital when the one-stage prothrombin time was 19s (control 15s); kaolin-cephalin time 53s (control 45s); thrombin time 7s (controls 8s). The 
serum alpha feto-protein was less than $25 \mathrm{ng} / \mathrm{ml}$ and there was BSP retention of $47 \%$ at $30 \mathrm{~min}$ (normal $=5 \%$ at $30 \mathrm{~min}$ ).

Moderate hepatosplenomegaly with reduced activity in the left lobe of the liver but with no focal lesions was noted on an isotopic liver scan. An ultrasound scan likewise produced evidence of hepatomegaly. Intrasplenic pressure of $48 \mathrm{~cm}$ of water was obtained when a splenoportogram, which outlined oesophageal varices, was carried out. Marked irregularity and distortion of the hepatic venous radicals with small occlusions were revealed by a right hepatovenogram, and this supported the diagnosis of veno-occlusive disease suggested from the liver biopsy. The left hepatic vein could not be cannulated.

Three weeks after admission a portarenal shunt was performed but this only lowered the portal venous pressure from 30 to $25 \mathrm{~cm}$ of water. At the same time the inferior vena caval pressure rose from 15 to $40 \mathrm{~cm}$ of water while the superior vena caval pressure remained at $10 \mathrm{~cm}$ of water throughout the procedure. No obstruction of the inferior vena cava or of the hepatic venous ostia could be palpated at this time by a finger passed down through the right atrium. The liver was grossly distended and had a congested blotchy appearance.

In the postoperative period ascites became more severe, necessitating the withdrawal of 5 to 10 litres of fluid daily. Anastomosis between the thoracic duct and the left internal jugular vein failed to control this; indeed on the second day after this operation the amount of ascitic fluid removed was 23650 $\mathrm{ml}$. A second shunting procedure was performed about two weeks later when a Dacron $\mathbf{H}$ graft was inserted between the superior mesenteric vein and the inferior vena cava. This caused an immediate slight fall in portal pressure but failed to control the continuing production of ascitic fluid which required withdrawal of 1 to 9 litres per day.

After the second shunting operation the patient developed a deep venous thrombosis of the left leg. The liver function tests remained only slightly abnormal until the terminal stages of the illness when there was evidence of renal dysfunction and septicaemia due to coliform organisms. Fuller details of the management of this case, particularly with regard to fluid and protein replacement, will be reported elsewhere.

\section{LIVER BIOPSIES}

Separate biopsies from the right and left lobes of the liver were each obtained on three occasions over a period of about one month. The first pair showed changes which were more marked in the left lobe biopsy. Centrilobular loss of hepatocytes was striking. No normal hepatic veins could be identified, and the lumen of one of these vessels was completely

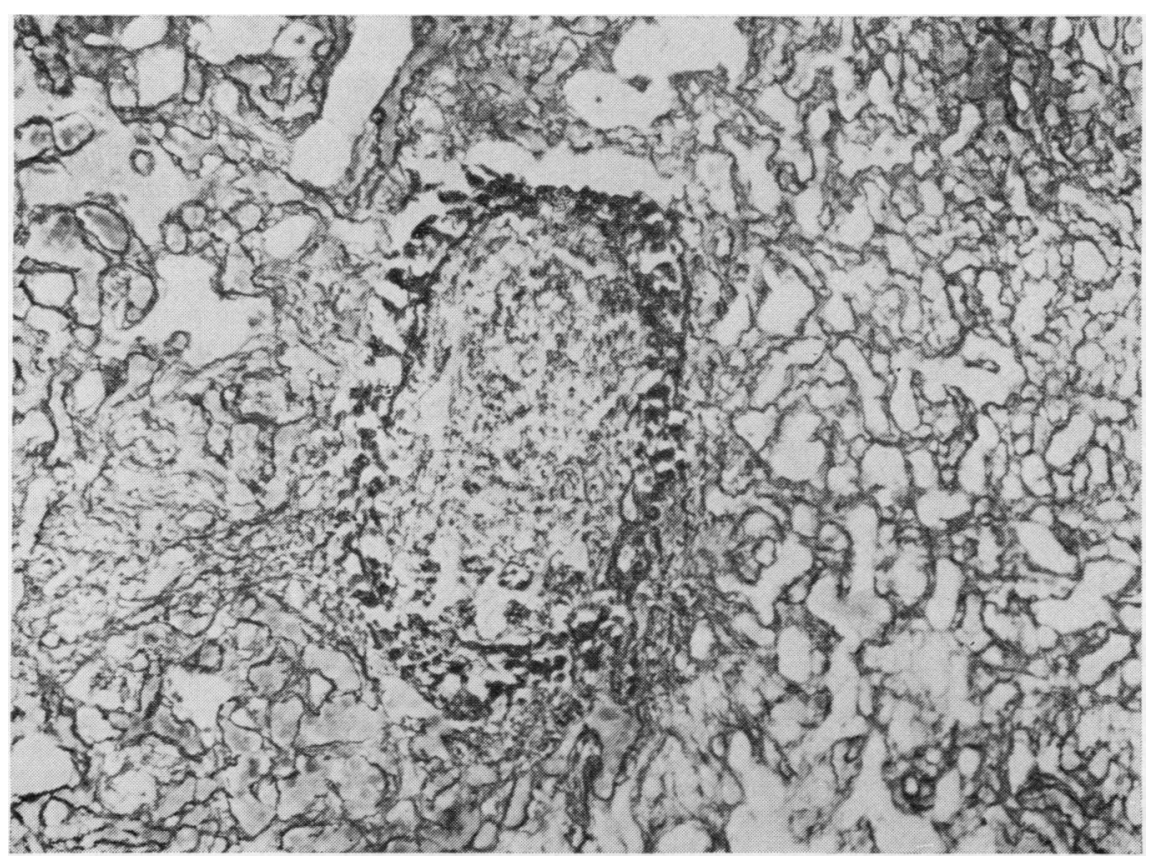

Fig 1 First biopsy from left lobe of liver. A centrilobular vein is occluded by loose connective tissue and surrounded by dilated sinusoids. Gordon and Sweet's reticulin stain $\times 175$. 
occluded by loose connective tissue (fig 1). In other lobules these veins were replaced by a few small capillary channels presumably derived from focal dilatation of sinusoids and separated from each other by similar loose connective tissue (fig 2 ). In some areas many red blood cells had exuded into this 은 loose tissue from intensely congested sinusoids, but this feature was very patchy. There was no evidence
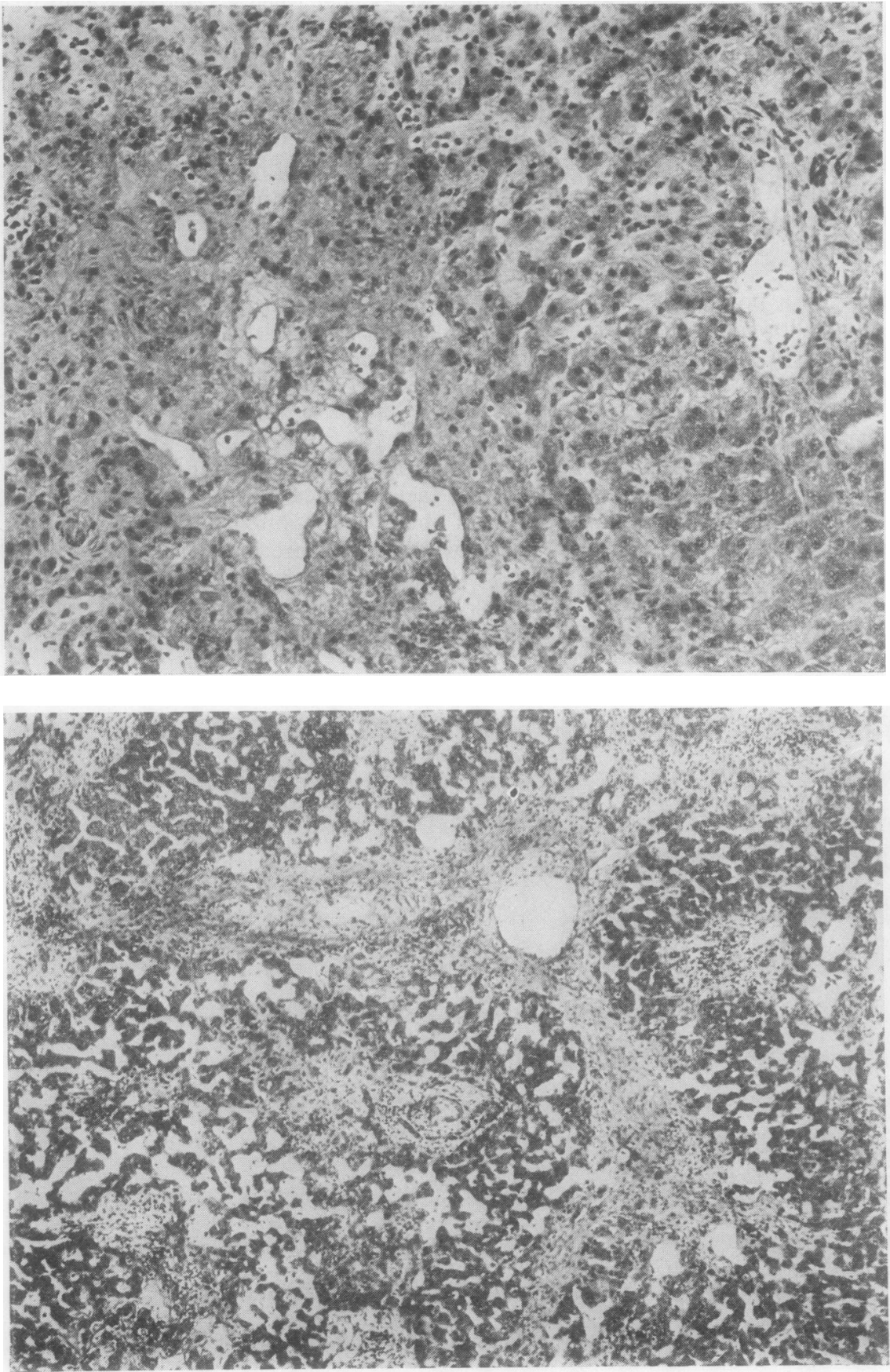

Fig 2 First biopsy

from left lobe of liver.

There is loss of hepatocytes from the centrilobular zone (left).

These are replaced by loose connective tissue surrounding dilated sinusoids. A normal portal tract is present on the right. Haemato$x y$ lin and eosin $\times 175$.

Fig 3 Second biopsy from right lobe of liver. There is mild portal hepatitis and fibrosis and more extensive fibrosis with septa radiating from a dilated central vein. There is also generalized sinusoidal dilatation. $H$ and $D$ $E \times 70$.

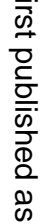

$\overrightarrow{0}$

$\overrightarrow{1}$

(1)

त)

ก

6

$\infty$

$\infty$

은

ब্ণ

잉

จำ

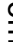

릉 $\stackrel{1}{3}$ 웅

울 욱 궁 N

N

N $\omega$

6 
of fibrin or platelet thrombi and no regenerative activity in surviving periportal hepatocytes. There was no hepatitis, no bile retention, and no stainable haemosiderin pigment. There was no evidence of well-established fibrosis although the loose areolar tissue referred to above was rich in young reticulin fibres.

The second biopsies were obtained 10 days later during the portarenal shunt operation. A needle biopsy from the left lobe showed changes similar to those described above although the sinusoidal congestion and extravasation of erythrocytes were more extensive. A wedge biopsy from the right lobe showed less severe acute changes. There was, however, a mild chronic portal hepatitis and rather more obvious fibrosis extending from both periportal and centrilobular zones (fig 3); this did not amount to true cirrhosis. Surviving hepatic veins showed varying degrees of subintimal fibrosis while others were replaced by empty dilated capillary vessels continuous with dilated sinusoids.

The third pair of liver biopsies were both needle biopsy specimens obtained three weeks postoperatively. These showed vascular changes no different from those already described, and again rather more severe in the tissue obtained from the left lobe of the liver.

\section{NECROPSY}

There was striking oedema of the lower limbs and abdominal distension due to ascites. Much of the ascitic fluid was serofibrinous in type but there were pockets of purulent exudate between the omentum and adherent loops of intestine. No bowel lesion could be demonstrated to account for this focal peritonitis which was related no doubt to recent abdominal paracentesis. It seems probable that this was the source of septicaemia and that endotoxaemia was the ultimate cause of death as there was no evidence of severe alimentary tract haemorrhage. A large pleural effusion had caused collapse of the right lung and some displacement of the mediastinal contents to the left. There was no defect in the diaphragm to account for this.

The liver, when dissected free from its surroundings, weighed $1700 \mathrm{~g}$. It was rather pale and soft and on section showed a striking mottled appearance especially throughout the left lobe and toward the anterior surface of the right lobe, due to intense venous congestion. There was no evidence of cirrhosis and no biliary abnormality. It was evident that neither portal-systemic venous shunt was operative. The portal renal shunt had contracted until the lumen was almost obliterated. The lumen of the Dacron $\mathbf{H}$ graft between the inferior vena cava and the superior mesenteric vein was completely occluded by fairly recent thrombus. There was no evidence of thrombosis elsewhere but the ostia of the hepatic veins were partly occluded by thin fibrous membranes. Beyond these obstructions within the liver the hepatic veins were wider but still showed some narrowing due to thin white tissue adherent to their walls; this process also extended into the small branches of these vessels. The portal, splenic, and superior mesenteric veins were quite patent and the hepatic artery likewise was normal. There was prominence of veins in the lower oesophagus and stomach, and the azygos and hemiazygos veins were grossly distended. The veins in the anterior abdominal wall and the falciform ligament were not congested. No other significant gross changes were evident at necropsy.

Histological examination of the liver revealed features similar to those already noted in the liver biopsies. In addition, partial or complete occlusion of the lumina of some larger hepatic veins by subintimal cellular connective tissue presented a very striking appearance (fig 4). A similar process extended into the main hepatic veins (fig 5). This same tissue appeared to contribute to the formation of the fibrous bands causing partial obstruction of the main hepatic veins at their ostia. However, these lesions included more mature dense collagen which was calcified in places. Subintimal fibroblast proliferation with areolar tissue formation involved a few small portal veins (fig 6); this was observed only in one block of tissue taken near the anterior surface of the right lobe. There was no evidence of organizing fibrin thrombi in any of these hepatic or portal vessels. A somewhat similar but rather more mature lesion involved some branches of the pulmonary artery in the lower lobe of the left lung. Histological examination of other organs and tissues showed no evidence of vascular disease. Histological examination of both kidneys did show recent cortical tubular degeneration or necrosis and extensive calcinosis.

\section{HERBAL TEA ANALYSIS}

Samples of maté tea obtained locally, and including some owned by the patient, were chemically analysed. Chromatographic and mass spectrometric evidence was obtained for the presence of pyrrolizidine alkaloids only in the patient's sample. These alkaloids were present in trace amounts and characterization of individual components was not possible.

\section{Discussion}

In retrospect the clinical features of this case with abdominal distention due to ascites, moderate hepatomegaly, and the absence of detectable 


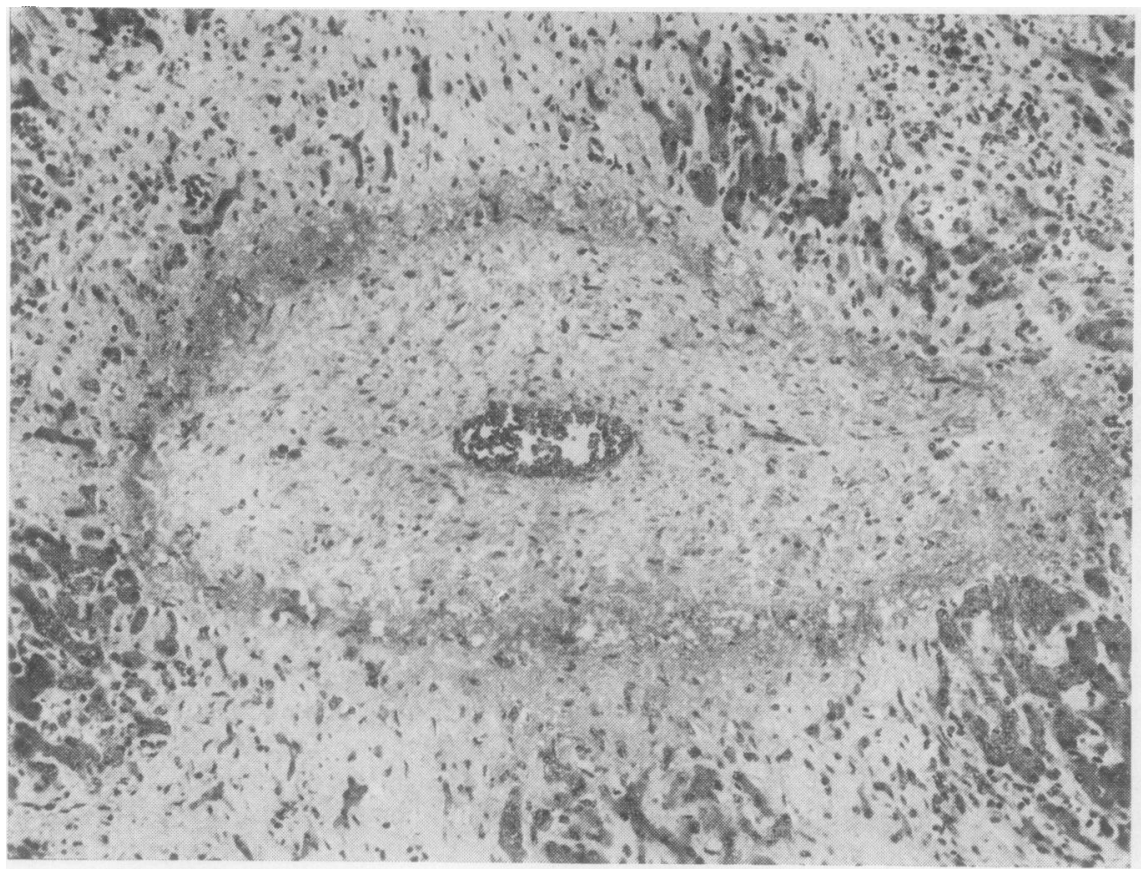

Fig 4 Postmortem liver. The lumen of a centrilobular vein is narrowed by subintimal $\vec{\varnothing}$ proliferation of connective tissue. Hand $E$ के $\times 117$.

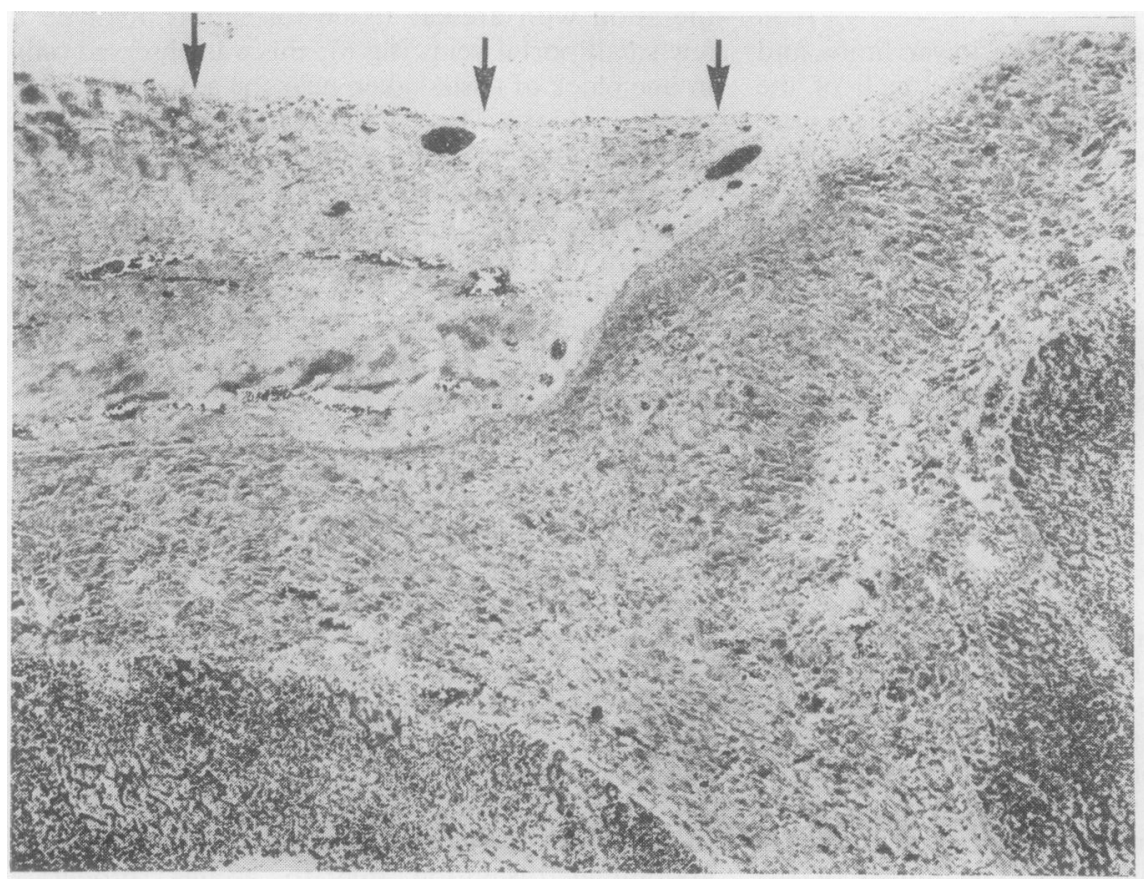

Fig 5 Postmortem liver. The ostium of a large hepatic vein is overlain with vascular connective tissue (arrows). The lumen of the vein extending into the liver is likewise occluded. $H$ and $E \times 35$. 응 


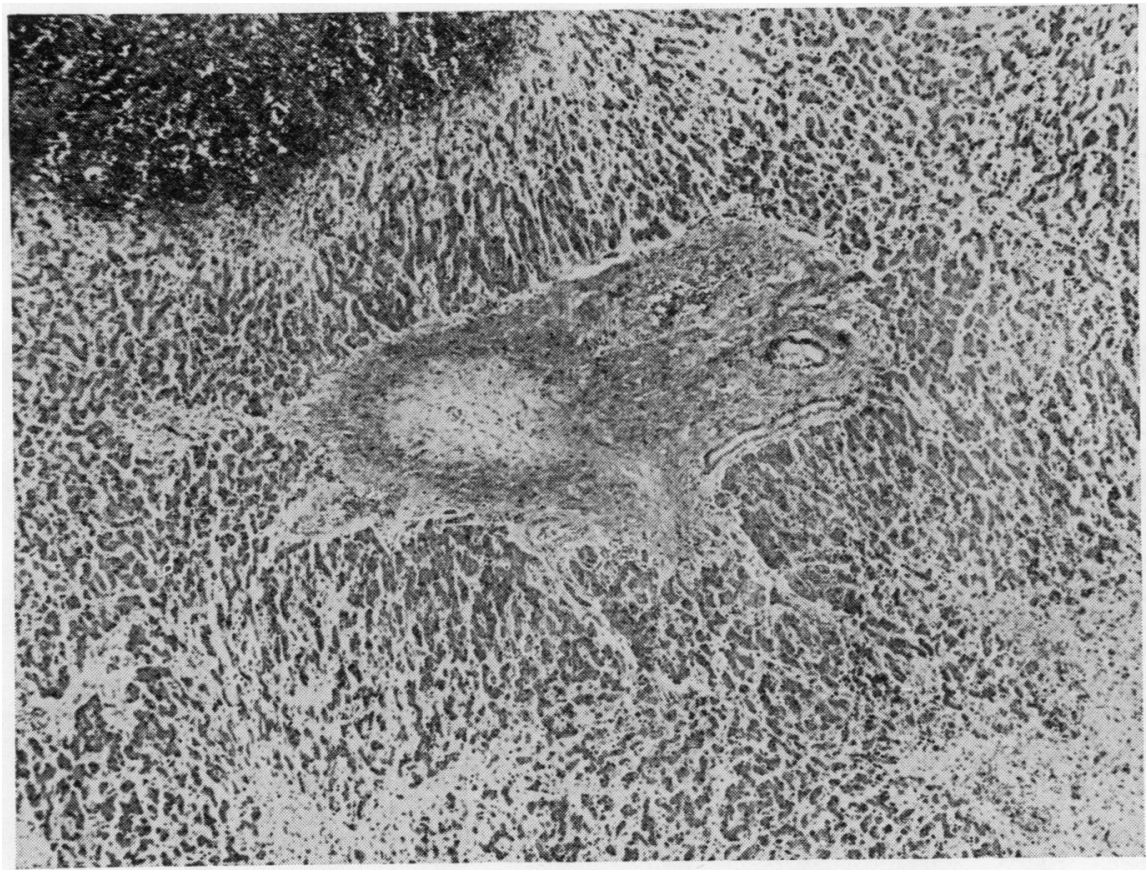

Fig 6 Postmortem liver. A portal tract showing portal venous occlusion.

splenomegaly and jaundice are typical of venoocclusive disease. It is hardly surprising, however, that the true nature of the condition was unsuspected until the first liver biopsy revealed centrilobular venous occlusion with intense sinusoidal congestion and hepatic cord atrophy. The diagnosis was supported by lack of evidence of extrahepatic portal venous obstruction, the hepatic venography pattern, and the history of herbal tea consumption. The liver biopsies showed that venous occlusion did not affect all vessels equally, and there was no advanced fibrosis or cirrhosis. Accordingly it was hoped that the condition might have been at a reversible stage. It is evident from the necropsy findings, however, that severe venous occlusion and fibrosis involved many parts of the liver, and it is probable that, even if life had been prolonged by patent portacaval shunts, a cardiac type cirrhosis could have developed.

Histological examination of the other organs and tissues failed to reveal any convincing evidence of generalized vascular disease. Some involvement of pulmonary arteries was noted similar to that observed in experimental animals given pyrrolizidine compounds (Lidberg, 1966; Allen et al, 1969). Involvement of portal as well as hepatic veins by subintimal fibrosis has been noted in human cases (Parker, 1959).

Certain cases of Budd-Chiari syndrome are due to fibrous bands causing occlusion of the inferior vena cava and the ostia of the hepatic veins. Such lesions are not normally associated with true veno-occlusive disease and their presence in this case raises problems of a cause and effect relationship. They appeared to be well established, consisting in part of dense fibrous tissue with foci of calcification. On the other hand, there was no evidence of their existence some months before death either by palpation during operation or from the results of venography. The calcification in these bands and the more severe calcification in the renal cortex may have developed over a relatively short period through parathyroid stimulation from the administration of large amounts of salt-poor albumin (Knox et al, 1974). On balance it seems more likely that these bands developed as an extension of the subintimal fibrotic process from the small hepatic veins, especially since both lesions were in physical continuity as observed at necropsy.

In any case it is difficult to ignore the history of herbal tea consumption. Small amounts only of toxic alkaloids were recovered from the sample owned by the patient, but she had ingested very large quantities of the tea over a period of about two years and it is possible that some earlier batches may have been more heavily contaminated. Contamination can vary with the degree of maturity of tea leaves when they are gathered, and this may explain why subsequent 
analysis of batches not owned by the patient have given negative results. It is clearly desirable to recognize this unusual cause of serious liver injury.

Dr D. Robins, Chemistry Department, University of Glasgow, kindly performed the chemical analysis of the herbal tea.

\section{References}

Allen, J. R., Carstens, L. A., and Katagiri, G. J. (1969). Hepatic veins of monkeys with veno-occlusive disease. Arch. Path., 87, 279-289.

Betty, R. W., and Markson, L. M. (1954). Liver biopsy in the diagnosis of ragwort (Senecio jacobea) poisoning, in a herd of cattle. Vet. Rec., 66, 398-400.

Bras, G., Jelliffe, D. B., and Stuart, K. L. (1954). Venoocclusive disease of liver with nonportal type of cirrhosis, occurring in Jamaica. Arch. Path., 57, 285-300.

Brodsky, I., Johnson, H., Killmann, S. A., and Cronkite, E. P. (1961). Fibrosis of central and hepatic veins, and perisinusoidal spaces of the liver following prolonged administration of urethane. Amer. J. Med., 30, 976-980.

Ecker, J. A., McKittrick, J. E., and Failing, R. M. (1966). Thrombosis of the hepatic veins. 'The Budd-Chiari syndrome'-a possible link between oral contraceptives and thrombosis formation. Amer. J. Gastroent., 45,
429-443.

Hoyumpa, A. M., Schiff, L., and Helfman, E. L. (1971). Budd-Chiari syndrome in women taking oral contraceptives. Amer. J. Med., 50, 137-140.

Knox, F. G., Schneider, E. G., Willis, L. R., Strandhoy, J. W., Ott, C. E., Cuche, J. L., Goldsmith, R. S., and Arnand, C. D. (1974). Proximal tubule reabsorption after hyperoncotic albumin infusion. Role of parathyroid hormone and dissociation from plasma volume. J. clin. Invest., 53, 501-507.

Lidberg, L. (1966). An experimental study of veno-occlusive disease (endophlebitis hepatica obliterans). Acta Soc. Med. upsallen, 71, 263-280.

McLean, E., Bras, G., and György, P. (1964). Veno-occlusive lesions in livers of rats fed Crotalaria fulva. Brit. J. exp. Path., 45, 242-247.

Parker, R. G. E. (1959). Occlusion of the hepatic veins in man. Medicine (Baltimore), 38, 369-402.

Reed, G. B., Jr., and Cox, A. J., Jr. (1966). The human liver after radiation injury. A form of veno-occlusive disease. Amer. J. Path., 48, 597-612.

Sherlock, S. (1961). Portal hypertension. In Progress in Liver Disease, edited by $\mathrm{H}$. Popper and F. Schaffer, vol. 1, O pp. 145-161. Heineman, London.

Stein, H. and Isaacson, C. (1962). Veno-occlusive disease of the liver. Brit. med. J., 1, 372-374.

Sterup, K., and Mosbech, J. (1967). Budd-Chiari syndrome after taking oral contraceptives. Brit. med. J., 4, 660. 